\title{
Nuthatch uses tool in London park
}

\author{
Christian Rutz $^{1^{*}}$ and Simon Deans ${ }^{2}$
}

${ }^{1}$ Centre for Biological Diversity, School of Biology, University of St Andrews, Sir Harold Mitchell Building, St Andrews KY16 9TH, UK

${ }^{2} 6$ Courtfield Rise, West Wickham, Kent BR4 9BE, UK

*Correspondence: Email: christian.rutz@st-andrews.ac.uk

\begin{abstract}
Here we report an observation of a Eurasian nuthatch Sitta europaea foraging with a tool in a public park in Greater London, UK. This record is of significance, as it: provides the first photographic evidence (to our knowledge) of nuthatch tool use; reveals an unusually wide phylogenetic and geographic distribution of tool behaviour within the Sittidae; and constitutes a rare example of animal tool use in an urban environment. To improve our understanding of nuthatch tool behaviour, we are building a global database of relevant anecdotal field observations - submissions are most welcome.
\end{abstract}

\section{Keywords}

extractive foraging, Hawaiian crow, New Caledonian crow, tool use, urban ecology, woodpecker finch

The use of foraging tools is very rare across the animal kingdom (Shumaker et al. 2011). Nuthatches are amongst the least-studied avian tool users, despite the fact that anecdotal observations have been reported for three 
North American species (Sitta pusilla, S. carolinensis, S. pygmaea) in at least six different localities (Morse 1968; Mitchell 1993; Pranty 1995; Slater et al. 2013; Gray et al. 2016; Figure 1c). Here we describe an observation of a distantly-related fourth species, the Eurasian nuthatch (S. europaea), using a wooden tool in a public park in the city of London, UK (Figure 1a, d), presenting what constitutes - to our knowledge - the first photographic documentation of nuthatch tool use.

On 19 June 2013, a pair of nuthatches was observed in South Norwood Country Park, in the London borough of Croydon. One of the birds was foraging for $c a .5$ minutes within the bark of a willow (Salix sp.) along the bank of a small stream. During this time, it used for $c a .10$ seconds a small piece of wood - most likely tree bark - as a tool (Figure 1a; Figure 2). The bird appeared to use the tool as a lever, attempting to lift scales of bark in search for hidden prey (compare with descriptions in Morse 1968; Pranty 1995; Gray et al. 2016). It used the same tool in two locations $c a .3$ metres apart within the same tree, holding it in its bill during deployment, but also putting it down for a few seconds (Figure 2). The bird was not observed to obtain prey with the tool, and after abandoning it wedged behind bark (the tool was not collected for further examination), resumed conventional foraging behaviour. The second nuthatch showed no apparent interest in this tool-use episode. Despite regular visits to the park since, no further tool-use observations have been made.

Our observation is of significance for several reasons. First, our photos provide important context for earlier reports of nuthatch tool use (Morse 1968; Mitchell 1993; Pranty 1995; Slater et al. 2013; Gray et al. 2016), documenting for the first time aspects of tool deployment, handling and transportation. They also offer a useful comparison for behaviours seen in other tool-using species, such as Hawaiian crows (use of bark foraging tools; Rutz et al. 2016) and New Caledonian crows (temporary storage of tools in-between foraging bouts; Hunt 1996; Klump et al. 2015). Second, our discovery considerably extends the known phylogenetic and geographic spread of tool use within the genus Sitta (Figure 1b, c), highlighting a 
remarkable propensity for this unusual foraging behaviour. Third, we provide a rare example of foraging tool use in an urban environment (see also Aguiar et al. 2014) - a habitat exhibiting very different ecological conditions compared to the forested areas where nuthatch tool use had previously been observed (Morse 1968; Mitchell 1993; Pranty 1995; Slater et al. 2013; Gray et al. 2016), and the remote tropical islands that are home to the most prominent avian tool users (woodpecker finch, Tebbich et al. 2010; New Caledonian crow, Hunt 1996; and Hawaiian crow, Rutz et al. 2016).

In light of an increasing number of anecdotal observations, across species and ecological contexts, nuthatch tool behaviour clearly deserves systematic investigation. It is particularly important to establish how much these birds rely on tool-assisted foraging (see Morse 1968) - that is, whether the behaviour is expressed sporadically by just a few birds (such as in the American crow: Caffrey 2000) or routinely by entire populations (New Caledonian and Hawaiian crow: Hunt 1996; Rutz \& St Clair 2012; Rutz et al. 2016). Nuthatches often handle seeds, bark flakes and other plant materials during foraging, food caching and nest construction (Matthysen 1998; del Hoyo et al. 2008; Slater et al. 2013). Tool use can easily be mistaken for these behaviours (note that our observation was made well after the typical nest-building period in Europe), and could be more common than previously thought (see Gray et al. 2016), both within and across nuthatch species. Over the coming years, we will attempt to chart the global distribution of nuthatch tool use, and we would be most grateful for the submission of reports of any relevant field observations (nuthatch@standrews.ac.uk).

\section{Acknowledgments}

S.D. made the observation and took photos, and C.R. wrote the paper; manuscript preparation was supported by BBSRC grant BB/G023913/2 to C.R. We thank the Rutz group, Mario Pesendorfer and an anonymous reviewer for constructive comments on earlier drafts. 


\section{References}

Aguiar, L. M., R. M. Cardoso, J. P. Back, E. C. Carneiro, A. Suzin, \& Ottoni, E. B. (2014). Tool use in urban populations of capuchin monkeys Sapajus spp. (Primates: Cebidae). Zoologia, 31, 516-519.

Caffrey, C. (2000). Tool modification and use by an American crow. Wilson Bulletin, 112, 283-284.

del Hoyo, J., A. Elliott, \& Christie, D. A. (eds.) (2008). Handbook of the birds of the world. Penduline-tits to Shrikes, vol. 13. Lynx Edicions, Barcelona.

Gray, M. M., E. W. Schunke, \& Cox, J. A. (2016). Tool usage by juvenile Sitta pusilla (Brown-headed Nuthatch). Southeastern Naturalist, 15, $\mathrm{N} 12-\mathrm{N} 15$.

Hunt, G. R. (1996). Manufacture and use of hook-tools by New Caledonian crows. Nature, 379, 249-251.

Klump B. C., J. E. M. van der Wal, J. J. H. St Clair, \& Rutz, C. (2015). Context-dependent 'safekeeping' of foraging tools in New Caledonian crows. Proceedings of the Royal Society of London, Series B, Biological Sciences, 282, 20150278.

Matthysen, E. (1998). The nuthatches. T \& AD Poyser, London.

Mitchell, T. L. (1993). Tool use by a white-breasted nuthatch. Bulletin of the Oklahoma Ornithological Society, 26, 6-7.

Morse, D. H. (1968). The use of tools by brown-headed nuthatches. Wilson Bulletin, 8, 220-224.

Pasquet, E., F. K. Barker, J. Martens, A. Tillier, C. Cruaud, \& Cibois, A. (2014). Evolution within the nuthatches (Sittidae: Aves, Passeriformes): molecular phylogeny, biogeography, and ecological perspectives. Journal of Ornithology, 155, 755-765.

Pranty, B. (1995). Tool use by brown-headed nuthatches in two Florida slash pine forests. Florida Field Naturalist, 23, 33-34.

Rutz, C., B. C. Klump, L. Komarczyk, R. Leighton, J. Kramer, S. Wischnewski, S. Sugasawa, M. B. Morrissey, R. James, J. J. H. St 
Clair, R. A. Switzer, \& Masuda, B. M. (2016). Discovery of specieswide tool use in the Hawaiian crow. Nature, 537, 403-407.

Rutz, C., \& St Clair, J. J. H. (2012). The evolutionary origins and ecological context of tool use in New Caledonian crows. Behavioural Processes, $89,153-165$.

Shumaker, R. W., K. R.Walkup, \& Beck, B. B. (2011). Animal tool behavior: the use and manufacture of tools by animals. Johns Hopkins University Press, Baltimore.

Slater, G. L., J. D. Lloyd, J. H.Withgott, \& Smith, K. G. (2013). Brownheaded Nuthatch (Sitta pusilla), version 2.0. In The birds of North America Online, P. G. Rodewald (ed.) (Cornell Lab of Ornithology: Ithaca), doi:10.2173/bna.349

Tebbich, S., K. Sterelny, \& Teschke, I. (2010). The tale of the finch: adaptive radiation and behavioural flexibility. Philosophical Transactions of the Royal Society of London, Series B, Biological Sciences, 365, 1099-1109. 
FIGURE CAPTIONS (2)

Figure 1 Nuthatch foraging tool use. (a) Nuthatch inserting wooden tool underneath the bark scale of a willow (for further details, see main text and Figure 2). (b) Nuthatch phylogeny (reproduced from Pasquet et al. 2014, with nuthatch drawings from del Hoyo et al. 2008, with permission from Springer and Lynx Edicions, respectively). (c) Global distribution of nuthatch tool-use observations (Sitta europaea - this study; S. pygmaea Pranty 1995; S. pusilla - Morse 1968, Pranty 1995, Gray et al. 2016; S. carolinensis - Mitchell 1993; all locations approximate; map adapted from file freely available on Wikimedia Commons). (d) Location of the present observation in London (map adapted from file freely available on Wikimedia Commons). Note: Tool-related behaviour in a non-foraging context has been reported for a fifth nuthatch species, $S$. canadensis (marked with a square in panel b), which sometimes uses bark pieces to apply tree resin to the entrance hole of its nests (del Hoyo et al. 2008).

Figure 2 Series of 21 photos (taken by Simon Deans) documenting an observation on 19 June 2013 of a nuthatch using a tool in a London park (South Norwood Country Park, London, UK). Photos are shown uncropped, and with camera-recorded timing information added (hh:mm:ss). 

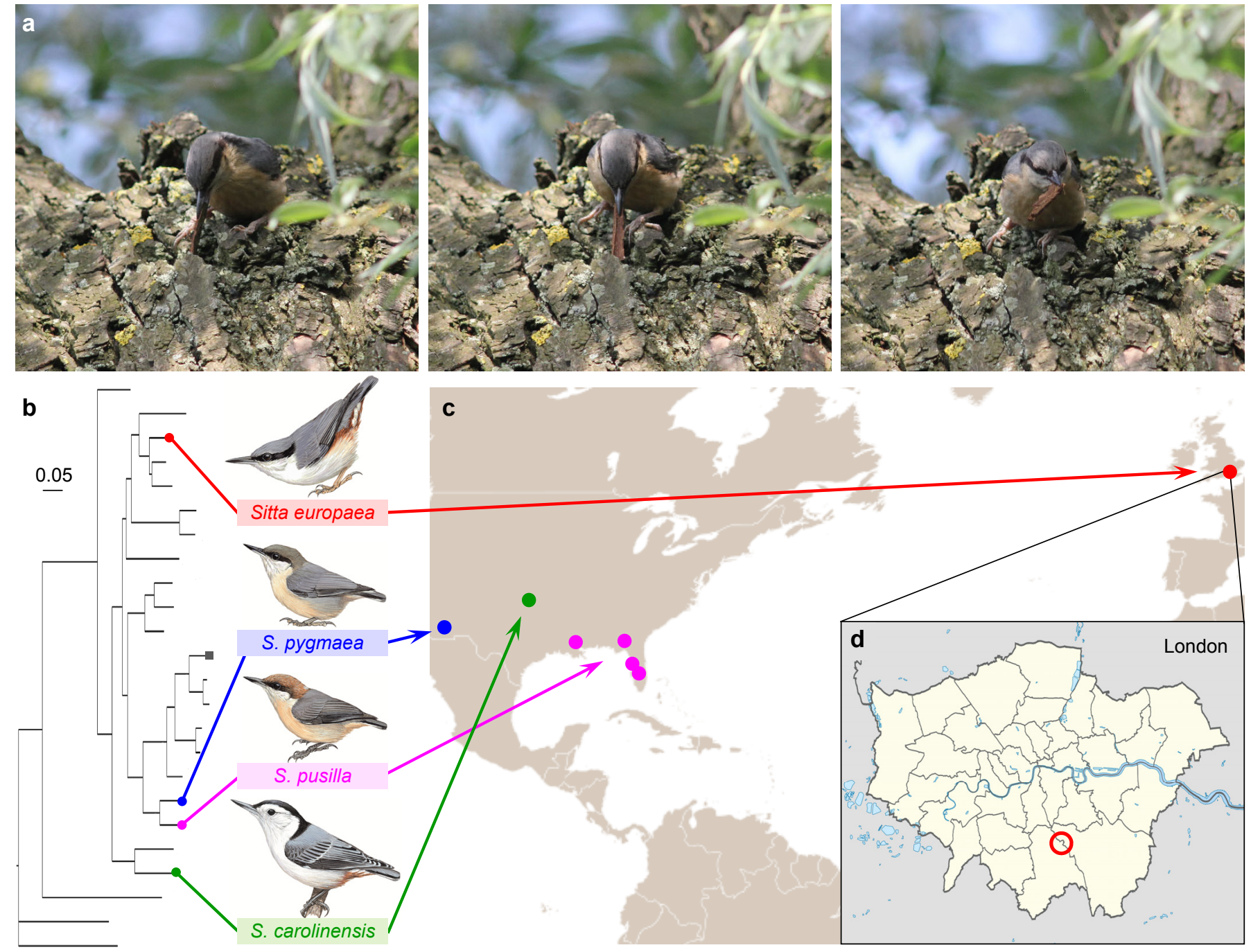

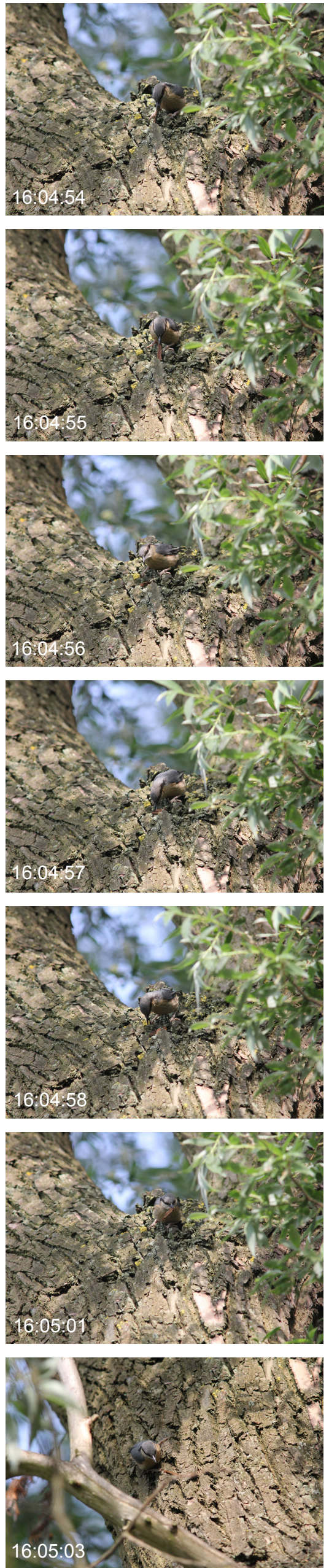
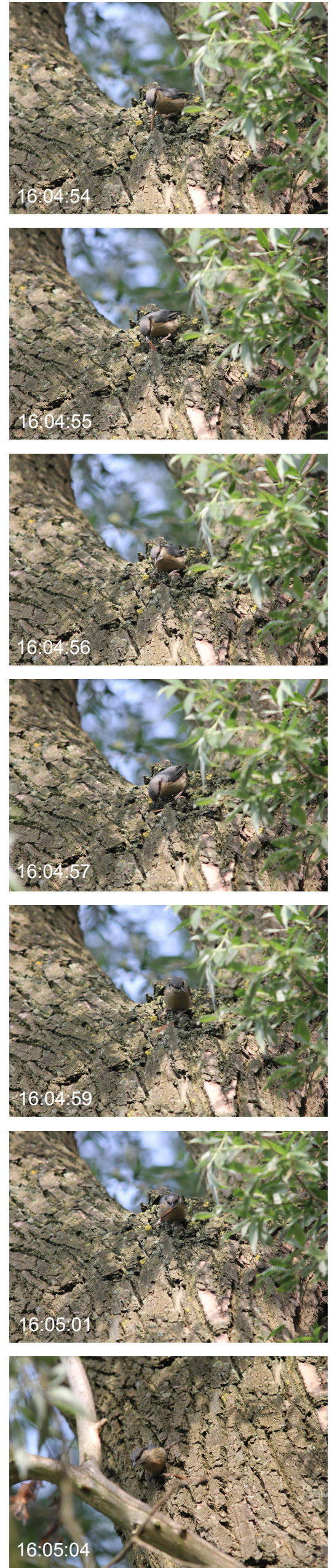
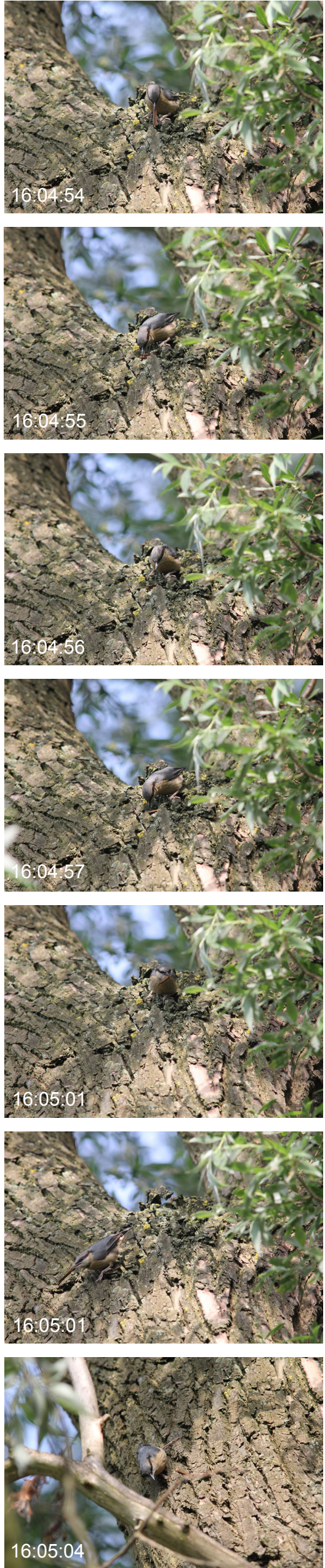